\title{
Effect of exogenous hyperinsulinaemia on atherogenesis in cholesterol-fed rabbits
}

\author{
B .G. N ordestgaard ${ }^{1,2}$, B . A gerholm-L arsen ${ }^{1}$, S. Stender ${ }^{3}$ \\ ${ }^{1}$ Department of Clinical Biochemistry, Herlev Hospital, University of Copenhagen, Denmark \\ ${ }^{2}$ Department of Clinical Biochemistry and Medicine B, Division of Cardiology, Rigshospitalet, University of Copenhagen, \\ Denmark \\ ${ }^{3}$ Department of Clinical Chemistry, Koege Hospital, Denmark
}

Summary To examine the hypothesis that hyperinsulinaemia promotes atherosclerosis, cholesterol-fed rabbits were injected subcutaneously with 6 IU of human insulin $(n=16)$ or placebo $(n=20)$ daily for 24 weeks; injection of insulin resulted in hyperinsulinaemia for up to $16 \mathrm{~h}$ after injection. Compared to placebo rabbits, insulin-treated rabbits had higher levels of insulin antibodies in plasma, similar levels of intermediate density, low density and high density lipoprotein cholesterol and similar activities of hepatic and lipoprotein lipase in post-heparin plasma, but lower levels of plasma C-peptide, blood glucose, postprandial plasma triglycerides, plasma cholesterol and very low density lipoprotein cholesterol. On univariate analysis, with and without adjustment for differences in plasma cholesterol levels between the two groups, there were no significant differences in extent or severity of atherosclerosis between insulin and placebo rabbits. Furthermore, after combining the results from all the rabbits to examine plasma insulin levels and the other variables mentioned above as predictors of atherosclerosis severity, plasma insulin level was not a predictor, on univariate or multiple linear regression analysis; the first ranked independent predictors were postprandial intermediate density lipoprotein cholesterol in the arch, and postprandial plasma triglyceride in both the thoracic and abdominal aorta. These results suggest that exogenous hyperinsulinaemia does not promote atherogenesis in cholesterol-fed rabbits, but that postprandial levels of intermediate density lipoprotein cholesterol or plasma triglycerides may be involved in atherogenesis. [Diabetologia (1997) 40: 512-520]

Keywords Atherosclerosis, C-peptide, diabetes mellitus, hepatic lipase, hyperinsulinaemia, insulin, insulin antibodies, intermediate density lipoprotein, lipoprotein lipase, postprandial triglycerides.
Coronary heart disease and thus atherosclerosis is the leading cause of death among patients suffering from diabetes mellitus; men and women with diabetes have a three to fivefold higher coronary heart disease mortality or incidence rate compared with non-diabetic

Received: 10 October 1996 and in revised form: 28 January 1997

Corresponding author: Børge G. Nordestgaard, Department of Clinical Biochemistry, Herlev University Hospital, DK-2730 Herlev, Denmark

A bbreviations: HDL, High density lipoprotein; IDL, intermediate density lipoprotein; LDL, low density lipoprotein; VLDL, very low density lipoprotein; IDDM, insulin-dependent diabetes mellitus; NIDDM, non-insulin-dependent diabetes mellitus. subjects [1]. Although a number of factors such as hyperglycaemia, dyslipidaemia, a procoagulant state, hyperinsulinaemia, glycation of proteins, oxidation or glycation of lipoproteins, as well as enhanced smooth muscle cell proliferation and foam cell formation, have all been suggested as possible links between diabetes and atherosclerosis [1], the increased risk of coronary heart disease among diabetic patients still remains largely unexplained.

Hyperinsulinaemia could be directly involved in atherogenesis [2], although this possibility is fiercely debated [3-6]. In patients with insulin-dependent diabetes (IDDM) exogenous hyperinsulinaemia exists due to intermittent injections of large amounts of insulin [1], and in patients with non-insulin dependent diabetes (NIDDM) endogenous hyperinsulinaemia 
is caused by increased insulin production secondary to insulin resistance [7]. Accordingly, it seems to be a very important question for diabetic patients as to whether hyperinsulinaemia in itself is a promotor of atherosclerosis.

The aim of the present study was to address this question experimentally using a well-known animal model for atherosclerosis research: we used the cholesterol-fed rabbit to examine whether subcutaneous injections of insulin resulting in exogenous hyperinsulinaemia promotes atherosclerosis. The rabbits were only fed small amounts of cholesterol, but for an extended period of time, thus maintaining a plasma cholesterol level equivalent to the high human level. Since injection of insulin may affect a number of other factors of importance for atherosclerosis, variation in such factors was taken into account: we measured levels of cholesterol, triglycerides, lipoproteins, insulin, C-peptide, insulin antibodies and glucose in the 'fasting' as well as in the postprandial state throughout the 24-week study period; levels of postheparin plasma lipoprotein lipase and hepatic lipase activities were measured twice.

\section{Materials and methods}

A nimals and study design. Forty adult female New Zealand White rabbits were assigned to two groups, insulin and placebo, such that the mean body weight was the same $(3.00 \pm 0.05 \mathrm{~kg})$ in both groups $(\mathrm{X} \pm \mathrm{SEM}$; range $2.5-3.6 \mathrm{~kg})$. The rabbits were weighed every third week throughout the 24-week experimental period; the mean weight increased steadily in both groups and at week 24 , insulin and placebo rabbits weighed $3.95 \pm 0.05$ and $3.89 \pm 0.04 \mathrm{~kg}$, respectively (no significant difference).

For the first 7 weeks, all rabbits were fed daily in the early morning with $100 \mathrm{~g}$ rabbit chow (Altromin 2113, Lage, Germany) containing $0.4 \%$ cholesterol (CH-UPS, Sigma, St.Louis, Mo., USA) and $5 \%$ corn oil (Oleum Maidis BP-80, Meco Benzon, Copenhagen, Denmark); during the last 17 weeks the $100 \mathrm{~g}$ chow was altered to contain $0.2 \%$ cholesterol and $2.5 \%$ corn oil (cholesterol was dissolved in corn oil at $120^{\circ} \mathrm{C}$ and subsequently mixed with the chow). Because only $100 \mathrm{~g}$ chow was fed daily, all rabbits began eating immediately upon feeding; however, the time when all the chow was eaten varied from rabbit to rabbit. Generally all rabbits finished their meal within 1-2 $\mathrm{h}$ after feeding, and there were no observed differences in eating patterns between insulin and placebo rabbits.

About $30 \mathrm{~min}$ after receiving chow, the rabbits were daily injected subcutaneously with $6 \mathrm{IU}$ of human insulin $(60 \mu \mathrm{l}$; $30 \%$ as soluble insulin and $70 \%$ as isophane insulin; Actraphane HM 100 IU/ml, Novo Nordisk, Bagsvaerd, Denmark) or placebo, respectively. In pilot experiments it was determined that the largest injectable amount of insulin before frequent episodes of hypoglycaemia appeared, was 6 IU daily. In spite of this, during the 24-week experiment four rabbits in the insulin group died or were removed from the experiment due to severe hypoglycaemia and two additional rabbits encountered hypoglycaemia once, but were revived by administration of intravenous glucose.
Blood samples of 10-12 ml were drawn from ear veins initially and every third week thereafter; at weeks 3, 9, 15, and 21 blood samples were drawn postprandially $3-4 \mathrm{~h}$ after feeding and injection, whereas at weeks $0,6,12,18$, and 24 blood samples were drawn in the 'fasting' state, i.e. about $23 \mathrm{~h}$ after the last feeding and injection. Additionally, at week 15 blood samples of $4 \mathrm{ml}$ were drawn every $3 \mathrm{~h}$ during a 24-h period from ten rabbits in each group.

The experiment was in accordance with Danish regulations for experiments on animals and the 'Principles of laboratory animal care' (NIH publication No. 85-23).

Insulin, C-peptide and glucose. Plasma insulin was measured using an enzyme-immunoassay based on the ELISA principle (Enzymun-Test Insulin; Boehringer Mannheim, Mannheim, Germany). When human and rabbit insulin (Novo Nordisk) were added to plasma samples, $104 \pm 1 \%(n=5)$ and $89 \pm 2 \%$ $(n=5)$ of the added amount of the two types of insulin was recovered with this assay, respectively.

$\mathrm{C}$-peptide in plasma was measured with a radioimmunoassay against human C-peptide (RIA Kit for Human C-peptide, Antiserum M1221; Novo Research Institute, Novo Nordisk). When human C-peptide (Novo Nordisk) was added to plasma samples, $83 \pm 3 \%(n=4)$ of the added amount was recovered with this assay. It was not possible to obtain purified rabbit $\mathrm{C}$ peptide and therefore the levels of C-peptide measured in the rabbits may not be accurate; however, comparison of levels between rabbits is still valid.

Blood glucose was measured with an enzymatic test after blood was mixed with perchloric acid (Glucose 14055, GlucDH-Method; Merck System, Darmstadt, Germany).

L ipids and lipoproteins. Very low density lipoprotein (VLDL, $\mathrm{d}<1.006 \mathrm{~g} / \mathrm{ml}$ ), intermediate density lipoprotein (IDL, 1.006 $<\mathrm{d}<1.019 \mathrm{~g} / \mathrm{ml}$ ), low density lipoprotein (LDL, 1.019 $<\mathrm{d}<1.063 \mathrm{~g} / \mathrm{ml}$ ) and high density lipoprotein (HDL, $\mathrm{d}>1.063$ $\mathrm{g} / \mathrm{ml}$ ) were separated by ultracentrifugation at $4{ }^{\circ} \mathrm{C}$ using a Beckman 50.3 Ti rotor (RAMCON A/s, Copenhagen, Denmark) or a Kontron TFT 45.6 rotor (Watford, Hertfordshire, U.K.) for at least $2.8 \times 10^{6} \mathrm{~g} \times \mathrm{h}$ in solvent densities of 1.006, 1.019 and $1.063 \mathrm{~g} / \mathrm{ml}$; VLDL particles in these animals are of the beta-VLDL type [8]. Cholesterol (CHOD-PAP, Boehringer Mannheim) was measured in plasma and lipoproteins, and triglycerides (GPO-PAP, Boehringer Mannheim) in plasma.

Insulin antibodies. The immune response to injection of human insulin into rabbits was measured with a radioimmunoassay to detect rabbit antibodies against human insulin and was kindly performed by Novo Nordisk. The values are expressed as percentage of radioactive insulin bound to antibodies after radioactivities were adjusted based on the radioactivity bound to serum from rabbits not exposed to human insulin.

L ipoprotein lipase and hepatic lipase. At weeks 20 and 22, postheparin plasma lipoprotein lipase and hepatic lipase activities were measured as follows [9,10]: between 3 and $4 \mathrm{~h}$ after the daily meal, blood samples were drawn into disodium EDTA, 10 min after intravenous injections of 200 units of heparin per $\mathrm{kg}$ body weight (SAD, Copenhagen, Denmark). Blood and plasma were kept at $4^{\circ} \mathrm{C}$ before freezing at $-80^{\circ} \mathrm{C}$ until assayed in duplicate. The following was added to each assay tube: $100 \mu \mathrm{l}$ of either $0.15 \mathrm{mmol} / \mathrm{l} \mathrm{NaCl}$ (low salt) or $3.55 \mathrm{mmol} / \mathrm{l} \mathrm{NaCl}$ (high salt), $5 \mu \mathrm{l}$ of plasma, $145 \mu \mathrm{l}$ $0.15 \mathrm{mmol} / \mathrm{l} \mathrm{NaCl}$ and $150 \mu \mathrm{l}$ substrate. Samples from weeks 20 and 22 were each measured using just one preparation of substrate which contained (per assay volume of $150 \mu \mathrm{l}$ ) $8.4 \mu \mathrm{l}$ of activator plasma (heat-inactivated rabbit plasma, $56^{\circ} \mathrm{C}$ for 
$30 \mathrm{~min}$ ), $1.49 \mathrm{mg}$ of triolein (Sigma), $0.94 \mu \mathrm{Ci}$ of ${ }^{3} \mathrm{H}$-triolein (NET 431 Triolein $\left[9,10-{ }^{3} \mathrm{H}(\mathrm{N})\right]$, NEN, Du Pont, Dreiech, Germany), $5.82 \mathrm{mg}$ of bovine serum albumin (essential fatty acid free, Sigma), and $90 \mu \mathrm{g}$ of Triton X-100 (Merck) all in $0.2 \mathrm{mmol} / 1 \mathrm{Tris}$ and $0.15 \mathrm{mmol} / \mathrm{l} \mathrm{NaCl}$ at $\mathrm{pH}$ 8.4. Samples were incubated at $37^{\circ} \mathrm{C}$ for $45 \mathrm{~min}$. The reaction was stopped with 1.4:1.2:1.0 (vol/vol/vol) methanol/chloroform/heptane [11] with ${ }^{14} \mathrm{C}$-oleic acid added (NEC-317 Oleic acid $\left[1-{ }^{14} \mathrm{C}\right], \mathrm{NEN}$, $\mathrm{Du}$ Pont) before borate buffer was finally added. Hepatic lipase activity (high salt) and lipoprotein lipase activity (low salt minus high salt) were expressed as $\mu \mathrm{mol}$ of non-esterified fatty acids released per min incubation time per $\mathrm{ml}$ of plasma.

A therosclerosis. At week 24, the rabbits were killed by intravenous injection of $50-100 \mathrm{mg}$ pentobarbital $/ \mathrm{kg}$ body weight $(50 \mathrm{mg} / \mathrm{ml})$. The aorta from the origin at the left ventricle to the common iliac arteries was dissected free, the adventitia carefully removed and the aorta opened longitudinally and rinsed with saline. The vessel was fixed with small pins on a cork board and the surface area outlined on underlying graph paper before being divided into three parts: the aortic arch at the level of the first intercostal arteries, the thoracic aorta at the origin of the coeliac trunk, and the abdominal aorta. Each part was photographed for later estimation of atherosclerosis extent using point counting [12]: the number of points covering intimal lesions was divided by the total number of points covering that arterial segment and the values expressed as percentage of the area covered with lesions. After being photographed, the intima-inner media was stripped from the outer media, each part was weighed and the tissues were stored at $-20^{\circ} \mathrm{C}$ until analysis.

The intima-inner media was minced and the lipids were extracted with chloroform/methanol (1:1, vol/vol) for $24 \mathrm{~h}$. Total cholesterol in the extract was determined by the LibermannBurchard method after saponification [13]; we had previously shown that separation of aortic total cholesterol into the free and esterified fraction in cholesterol-fed rabbits is not superior to the measurement of total cholesterol alone [14]. The aortic cholesterol content is also closely associated with other indices of atherosclerosis in rabbits and pigs $[15,16]$.

\section{Statistical analysis}

Statistical analyses were performed with the SPSS [17] or Minitab program [18]. Differences between insulin and placebo rabbits were compared using Student's t-test or Wilcoxon's signed rank procedure. Additionally, univariate and multiple linear regression of the independent variables in the Figures and Table 1 as predictors of atherosclerosis severity in all rabbits were performed simultaneously. To achieve near-normal distribution of variables, plasma insulin, plasma triglycerides, plasma insulin antibodies and cholesterol content in the thoracic and abdominal aorta were transformed logarithmically and cholesterol content in the aortic arch was square root transformed prior to linear regression analysis or Student's ttest. Values are shown as means \pm SEM. A p-value of less than 0.05 on two-sided tests was considered statistically significant.

\section{Results}

Subcutaneous injection of 6 IU of human insulin (30\% soluble insulin and $70 \%$ isophane insulin) into cholesterol-fed rabbits resulted in exogenous
Table 1. Lipoprotein lipase and hepatic lipase activities in cholesterol-fed rabbits injected with insulin and placebo, respectively

\begin{tabular}{llc}
\hline & Week 20 & Week 22 \\
\hline L ipoprotein lipase activity & $\left(\mathrm{nmol} \mathrm{NEFA} \cdot \mathrm{min}^{-1} \cdot \mathrm{ml} \mathrm{plasma} \mathrm{m}^{-1}\right)$ \\
Insulin $(\mathrm{n}=16)$ & $717 \pm 55$ & $774 \pm 65$ \\
Placebo $(\mathrm{n}=20)$ & $772 \pm 52$ & $825 \pm 67$ \\
H epatic lipase activity & & \\
Insulin $(\mathrm{n}=16)$ & $166 \pm 9$ & $182 \pm 11$ \\
Placebo $(\mathrm{n}=20)$ & $194 \pm 9^{\mathrm{a}}$ & $207 \pm 12$ \\
\hline
\end{tabular}

Values are means \pm SEM.

${ }^{a} p<0.05$ when compared with the insulin group at week 20 using Student's t-test. Other values did not differ between insulin and placebo rabbits $(p>0.05)$

NEFA $=$ non-esterified fatty acids

hyperinsulinaemia for up to $16 \mathrm{~h}$ after injection (Fig.1). In the 'fasting' state, i.e. $23 \mathrm{~h}$ after the last meal and injection, plasma insulin was only marginally higher in insulin injected compared with placebo injected rabbits (Fig. 2). As ascertained from plasma C-peptide levels, rabbits injected with insulin exhibited depressed endogenous insulin production during the whole 24-h period (Figs. 1, 2). Blood glucose was depressed markedly within 3-4 h after insulin injection, but to a large extent was not affected during the remaining part of the day (Figs. 1,2); four rabbits died or were removed from the experiment due to episodes of severe hypoglycaemia.

The postprandial plasma triglyceride response was depressed from 13 to $19 \mathrm{~h}$ after the daily meal in rabbits injected with insulin (Figs. 1,2). This depression was not explained by a larger activity of lipoprotein lipase or hepatic lipase in post-heparin plasma in insulin-treated rabbits (Table 1). Interestingly, the maximal response in plasma triglycerides in placebo rabbits occurred approximately $14 \mathrm{~h}$ after the meal, in contrast to humans in whom the maximal response occurs 3-4 h after a fatty meal [19]. Accordingly, the postprandial plasma triglyceride level measured 3$4 \mathrm{~h}$ after the meal (Fig. 2) is not representative for plasma triglycerides during the entire postprandial phase (Fig. 1).

To achieve plasma cholesterol levels in the high human range around $20 \mathrm{mmol} / \mathrm{l}$, rabbits were fed 0.4 $\mathrm{g}$ cholesterol daily for the first 7 weeks and $0.2 \mathrm{~g}$ thereafter. In spite of the same dietary intake of cholesterol, at some time points insulin-treated rabbits had lower plasma cholesterol levels than placebo rabbits (Fig. 3). This difference mainly reflected a lower VLDL (i.e. beta-VLDL) cholesterol level in insulintreated rabbits, whereas at most time points plasma levels of IDL, LDL and HDL cholesterol were similar in the two groups, in the 'fasting' as well as the postprandial state (Fig. 3).

Antibodies against human insulin developed gradually in 8 of 16 rabbits injected with insulin for 24 weeks. The rabbits in the insulin-treated group 


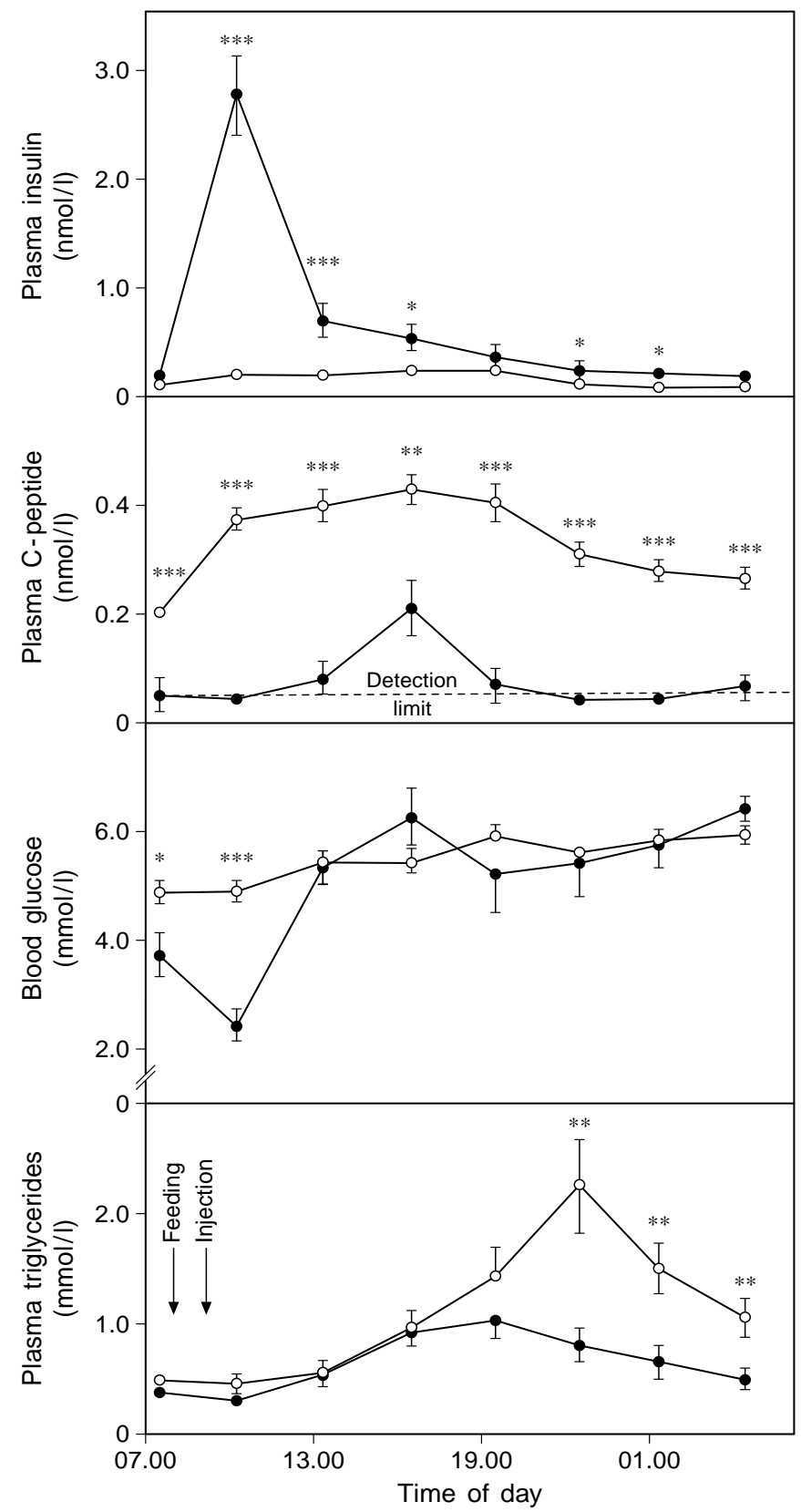

Fig. 1. Plasma insulin, plasma C-peptide, blood glucose and plasma triglycerides during a 24 -h period at week 15 in 10 insulin and 10 placebo treated rabbits. Values are means \pm SEM. Individual values of plasma C-peptide below the detections limit where given the value 0 when mean values were calculated. Differences between insulin and placebo rabbits at a given point were tested with Student's t-test: $* p<0.05$, $* * p<0.01, * * * p<0.001$; no asterisk indicates insulin and placebo rabbits did not differ $(p>0.05)$. To approach normal distribution plasma insulin and triglycerides were transferred logarithmically $\left(\log _{10}\right)$ before t-tests, but untransformed values are shown. Insulin $(n=10) ; \bigcirc$, placebo $(n=10)$

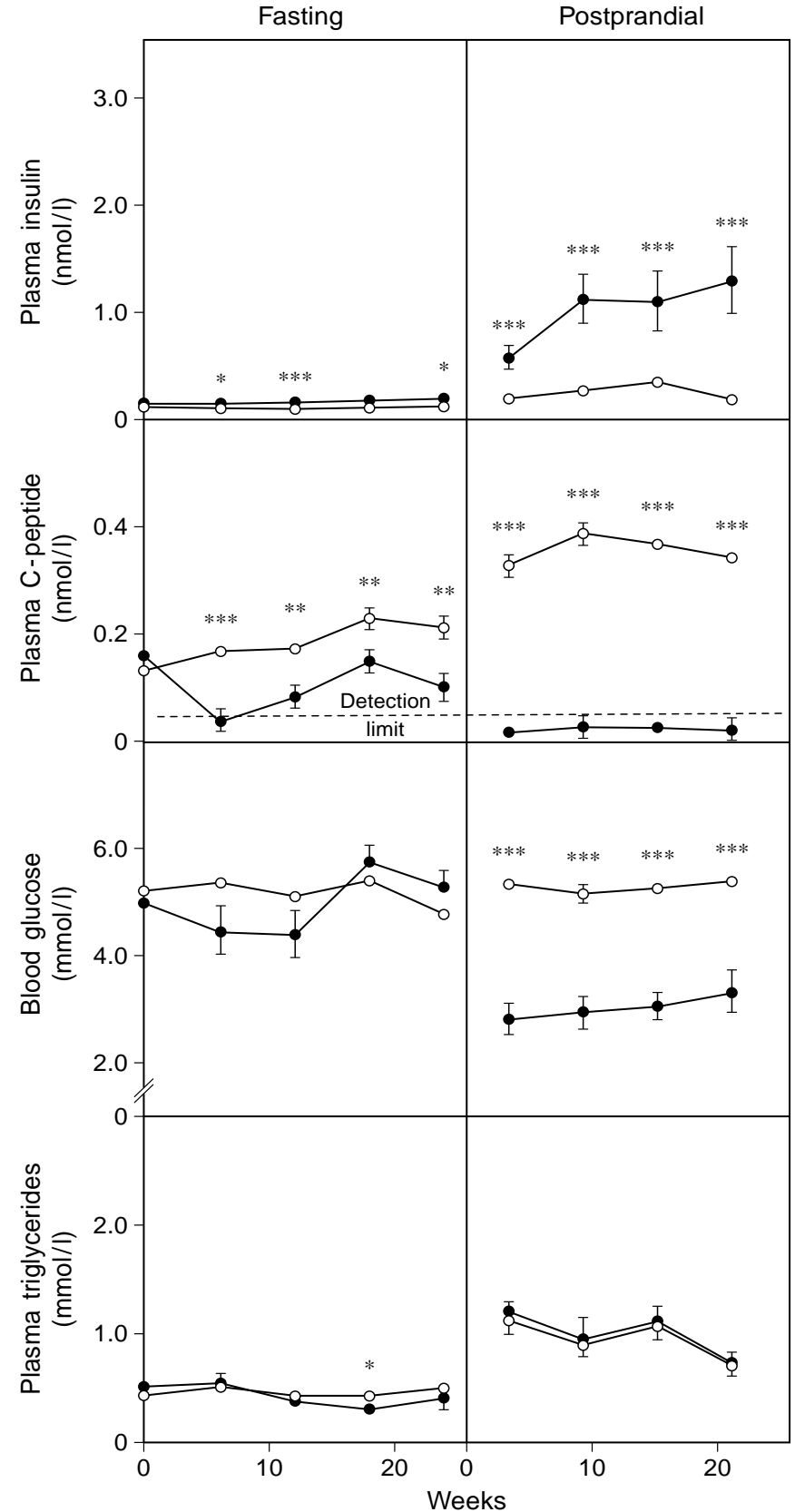

Fig. 2. Plasma insulin, plasma C-peptide, blood glucose and plasma triglycerides in the 'fasting' ( $23 \mathrm{~h}$ after last meal) and postprandial state (3-4 h after last meal) during the 24-week experimental period. Values are means \pm SEM. Individual values of plasma C-peptide below the detections limit where given the value 0 when mean values were calculated. Differences between insulin and placebo rabbits at a given point were tested with Student's t-test: $* p<0.05, * * p<0.01$, $* * * p<0.001$; no asterisk indicates insulin and placebo rabbits did not differ $(p>0.05)$. To approach normal distribution plasma insulin and triglycerides were transferred logarithmically $\left(\log _{10}\right)$ before t-tests, but untransformed values are shown. Insulin $(n=16) ; \bigcirc$, placebo $(n=20)$ 


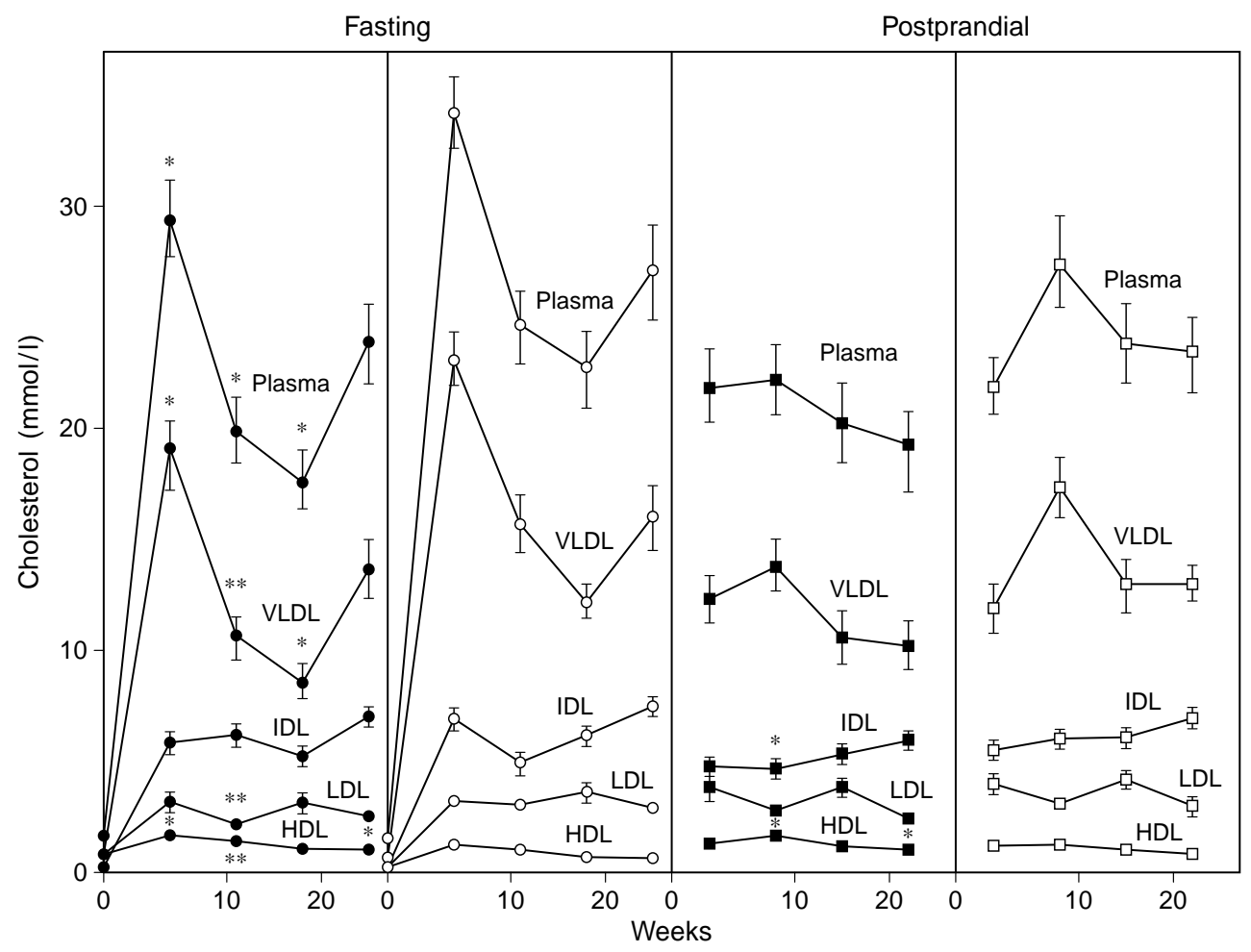

Fig. 3. Cholesterol in plasma and in very low density lipoprotein (VLDL), intermediate density lipoprotein (IDL), low density lipoprotein (LDL), and high density lipoprotein (HDL) in cholesterol-fed rabbits injected with insulin or placebo. Rabbits were fed $0.4 \mathrm{~g}$ cholesterol daily during the first 7 weeks and $0.2 \mathrm{~g}$ cholesterol during the remaining period. Values are means \pm SEM. Fasting and postprandial values are indicated separately. Differences between insulin and placebo rabbits at a given time point were tested with Student's t-test: $* p<0.05$, and $* * p<0.01$; no asterisk indicates insulin and placebo rabbits did not differ $(p>0.05)$. $\square$, Insulin $(n=16)$; $\bigcirc$, placebo $(n=20)$

had higher levels of insulin antibodies on average than the placebo rabbits (Fig. 4).

When all insulin and placebo rabbits were compared on univariate analysis (Wilcoxon's signed rank procedure), there were no significant differences in extent (\% intima with lesions) or severity of atherosclerosis (aortic cholesterol content) between the two groups, in arch, thoracic or in the abdominal aorta (Fig. 5, left panels). To normalize for differences in plasma cholesterol levels between the two groups, rabbits in the two groups were matched for plasma cholesterol levels leading to two new groups consisting of 15 rabbits with almost identical mean plasma cholesterol levels (Fig.5, right panels); even then, there was still no significant difference in the extent or severity of atherosclerosis in the three aortic sites between the two groups.

On neither univariate nor stepwise multiple linear regression analysis were 'fasting' or postprandial plasma insulin levels a predictor of atherosclerosis severity; the independent variables shown in Figures 2-4 (except total plasma cholesterol) and Table 1 as predictors of the dependent variable of atherosclerosis severity (Fig. 5, lower left panel) were performed on all rabbits combined. In the three aortic sites, the first ranked independent predictor was postprandial IDL cholesterol in the arch, and postprandial plasma triglyceride levels in both the thoracic and abdominal aorta (Table 2); in all three sites HDL cholesterol level was the only other independent predictor.

\section{Discussion}

One important new observation in the present study is the lack of difference in the extent and severity of atherosclerosis between cholesterol-fed rabbits injected with insulin and placebo, despite hyperinsulinaemia in insulin-treated rabbits for up to $16 \mathrm{~h}$ after injection daily for 24 weeks. Previous animal studies [20-23] have examined the effect of hyperinsulinaemia in models not generally designed to study atherosclerosis, i.e. where there were very low levels of atherogenic lipoproteins. These studies found increased arterial content of lipid [20], triglycerides [21-23], or smooth muscle cells [23] in hyperinsulinaemic animals, however, never showed an increased arterial content of cholesterol or foam cells, hallmarks of early human atherosclerosis [24]; on the other hand cholesterol deposition and foam cells are characteristics of atherosclerosis in cholesterol-fed rabbits [24] where the abnormal beta-VLDL particle is probably the main cause of atherosclerosis [8]. 


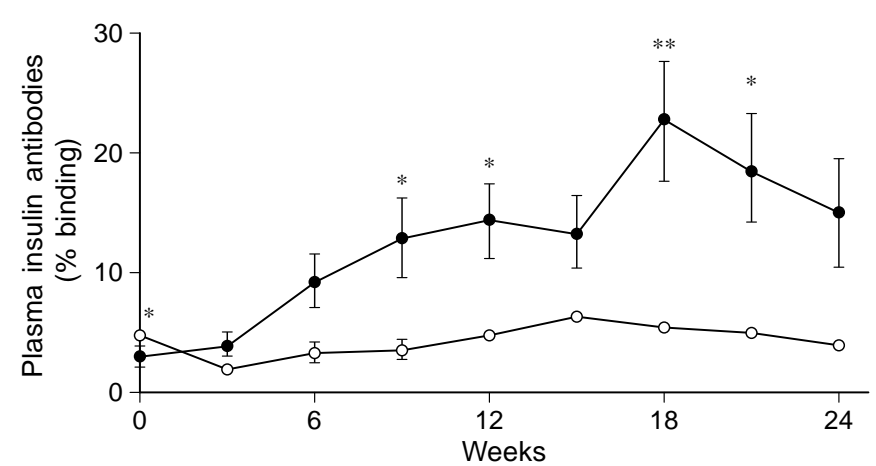

Fig. 4. Plasma insulin antibodies in cholesterol-fed rabbits injected with human insulin or placebo during 24 weeks. Values are means \pm SEM. A difference between insulin and placebo rabbits at a given time point was tested with Student's t-test: $* p<0.05$, and $* * p<0.01$; no asterisk indicates insulin and placebo rabbits did not differ $(p>0.05)$. To approach normal distribution values were transformed logarithmically $\left(\log _{10}\right)$ before t-tests, but untransformed values are shown. Insulin $(n=16) ; \bigcirc$, placebo $(n=20)$

Therefore, taken together, the experimental evidence does not suggest a direct role for insulin in promoting atherosclerosis.

We chose to study the effect of exogenous hyperinsulinaemia in non-diabetic rather than in diabetic rabbits. Therefore, we only studied the effect of insulin injections, whereas when diabetic, insulin-injected rabbits were compared with non-diabetic rabbits, as in our previous study [25], the effect of diabetes and insulin injections were studied simultaneously. Insulin injections in that previous study in cholesterol-fed rabbits were also found not to promote atherogenesis, and these rabbits most likely also had exogenous hyperinsulinaemia since they received 3.8 IU of insulin per kg daily compared with 1.7 IU per kg daily in the present study. For comparison, in the University Group Diabetes Program patients with NIDDM in insulin-treated groups received between 0.2 and 0.6 IU of insulin per kg daily [26] (we assumed an average weight of $70 \mathrm{~kg}$ for participants), and in the Diabetes Control and Complications Trial patients with IDDM in the conventional therapy group received 0.6-0.7 IU insulin per $\mathrm{kg}$ daily [27]. Since we are not aware of reports from these studies on 24-h plasma insulin curves in diabetic patients in response to insulin injections, we were not able to compare directly the level of hyperinsulinaemia in the present study with that in insulin-treated diabetic patients; on average throughout the entire 24-h period, insulin-treated rabbits in the present study had 3.8-fold higher plasma insulin levels compared with placebo-treated rabbits. However, extrapolation from the present data obtained in non-diabetic rabbits to humans, particularly to insulin-treated diabetic patients, requires caution.

The interest in insulin as a cardiovascular risk factor stems originally from three large population studies in Helsinki [28], Paris [29] and Busselton,

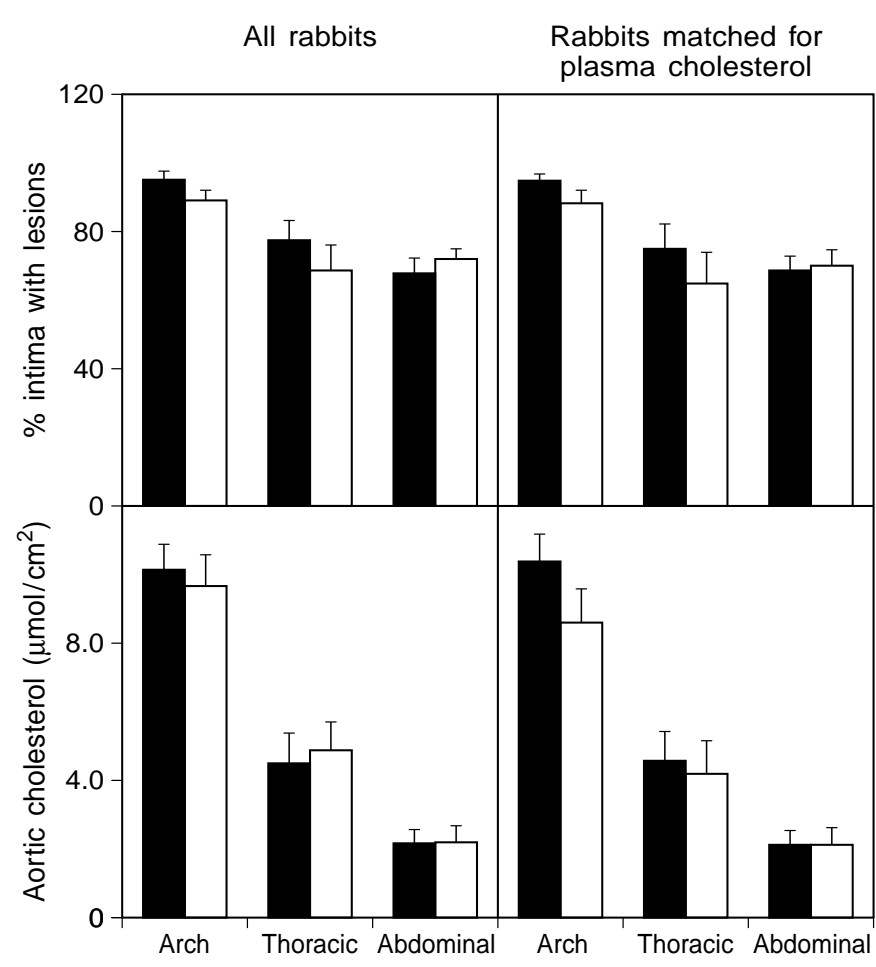

Fig. 5. Extent (\% intima with lesions) and severity (aortic cholesterol content) of atherosclerosis in all insulin and placebo injected cholesterol-fed rabbits ( $\square$, insulin, $n=16$; $\square$ placebo, $n=20)$ and in a subgroup of the rabbits matched for plasma cholesterol $(\square$, insulin, $n=15 ; \square$, placebo, $n=15)$. Values are means \pm SEM. In neither of the 12 comparisons did insulin and placebo rabbits differ $(p>0.05)$ on Wilcoxons' signed rank procedure

Australia [30], where high insulin levels were shown to be associated with increased incidence and mortality rates of coronary heart disease. Whether this association is causal is still the subject of much debate [36]. Neither insulin injection compared with placebo in patients with NIDDM in the University Group Diabetes Program, nor intensive insulin treatment compared with conventional insulin treatment in patients with IDDM in the Diabetes Control and Complications Trial, led to increased cardiovascular incidence or mortality [26]. These results also do not support the hypothesis that insulin promotes atherosclerosis directly. One possible explanation for these apparently conflicting results is that hyperinsulinaemia is a marker for the insulin resistance syndrome [5-7], characterised by a cluster of cardiovascular risk factors such as a degree of glucose intolerance, an increase in plasma triglycerides, a reduction in HDL cholesterol levels, high blood pressure, hyperuricaemia, small dense LDL particles, obesity, and high levels of plasminogen activator inhibitor 1 . One or more of these risk factors could be causally related to atherosclerosis and coronary heart disease, and thereby account for the observed association between high insulin levels and coronary heart disease. 
Table 2. Ranking of independent variables as predictors of aortic cholesterol content in cholesterol-fed rabbits

\begin{tabular}{|c|c|c|c|c|c|c|}
\hline \multirow[t]{2}{*}{ Rank } & \multicolumn{2}{|l|}{ Arch } & \multicolumn{2}{|l|}{ Thoracic } & \multicolumn{2}{|l|}{ Abdominal } \\
\hline & Predictor & Cum. $\mathrm{R}^{2}$ & Predictor & Cum. $R^{2}$ & Predictor & Cum. $R^{2}$ \\
\hline 1 & Postprandial IDL & 0.26 & Postprandial TG & 0.32 & Postprandial TG & 0.37 \\
\hline 3 & Postprandial HDL & 0.44 (inversely related) & & & & \\
\hline
\end{tabular}

Stepwise multiple linear regression with the independent variables shown in Figures 2-4 and Table 1, except total plasma cholesterol, was performed; in each rabbit for each fasting and postprandial variable shown in Figures 2 and 3 the timeaveraged value (area under curve) was used, for insulin antibody levels the time-averaged value including both values

Another interesting new observation in the present study is that on multivariate analysis postprandial plasma triglycerides and IDL levels were the best independent predictors of atherosclerosis severity; in the postprandial state the IDL fraction contains a mixture of IDL of hepatic origin and chylomicron remnants. It is important to note that postprandial values in this analysis represent values $3-4 \mathrm{~h}$ after the meal and not $13-15 \mathrm{~h}$ after the meal where plasma triglycerides reached maximal values in placebo rabbits. That postprandial lipoproteins and in particular remnant lipoproteins (IDL, small VLDL, chylomicron remnants) could be important for atherogenesis was originally proposed by Zilversmit [31, 32]. IDL levels have also been found to be strong predictors of atherosclerosis in genetically hyperlipidaemic [33] and cholesterol- or casein-fed rabbits [34]. In humans without major genetic or secondary forms of hyperlipidaemia, IDL and small VLDL have been shown to be independent predictors of the presence, severity, or progression of atherosclerosis [35-39]. $\mathrm{Pa}-$ tients with type III hyperlipoproteinaemia [8], chronic renal failure [40] or NIDDM [41] have elevated levels of remnant lipoproteins as well as accelerated development of atherosclerosis. Finally, elevated postprandial levels of triglycerides or remnant lipoproteins have also been found to be predictors of the presence, severity, progression or familial risk of atherosclerosis [42-48]. The present results therefore add to the growing evidence that remnant lipoproteins in the postprandial state may be involved directly in promoting atherosclerosis.

The mechanism by which remnant lipoproteins or smaller triglyceride-rich lipoproteins such as chylomicron remnants and small VLDL and IDL particles could promote atherosclerosis directly, would involve transfer of these particles into the intima [49-50], where such particles appear to be retained selectively [50-51]. In contrast to LDL, smaller triglyceride-rich lipoproteins without prior modification can then be taken up directly by macrophages to produce foam cells $[1,52]$, a key cell type of the atherosclerotic plaque [24]. from fasting and postprandial blood samples was used, and for lipoprotein lipase and hepatic lipase activities the mean value of the two measurements were used. Only predictors that were independently statistically significant $(p<0.05)$ were ranked.

TG, Plasma triglycerides; Cum. $\mathrm{R}^{2}$, cumulative $\mathrm{R}^{2}$

Surprisingly, fasting HDL cholesterol was independently positively associated with aortic cholesterol content at all three aortic sites. This could imply an atherogenic effect of HDL in these animals, which is very different from the supposed anti-atherogenic effect of HDL in humans. However, in cholesterolfed rabbits such as those in the present study only 3 $7 \%$ of plasma cholesterol is in the HDL fraction, in contrast to $16-26 \%$ in humans [53]. Accordingly, the cholesterol-fed rabbit may not be a very good model for studying the influence of HDL cholesterol on atherogenesis, at least not if the aim is to mimic the situation in humans.

In summary, exogenous hyperinsulinaemia did not appear to promote atherogenesis in cholesterol-fed rabbits; however, postprandial levels of triglycerides and particles in the IDL range were the best independent predictors of atherosclerosis severity.

A cknowledgements. We owe thanks to Novo Nordisk and many of its personnel for providing insulin, placebo, rabbits, animal facilities, technical assistance, kits for measuring Cpeptide, human and rabbit insulin calibrators, human C-peptide calibrators, advice and for measuring plasma insulin antibody levels. Also, we would like to thank Mr. K. S. Jensen for providing skillful technical assistance and Ms. E. Quist for typing the manuscript. This study was supported by the Danish Heart Foundation, the Danish "Fonden til Laegevidenskabens Fremme" and the Danish "Novo's Fonds Komite".

\section{References}

1. Bierman EL (1992) Atherogenesis in diabetes. Arterioscler Thromb 12: 647-656

2. Stout RW (1994) The impact of insulin upon atherosclerosis. Horm Metab Res 26: 125-128

3. Jarrett RJ (1994) Why is insulin not a risk factor for coronary heart disease? Diabetologia 37: 945-947

4. Fontbonne A (1994) Why can high insulin levels indicate a risk for coronary heart disease? Diabetologia 37: 953-955

5. Stern MP (1994) The insulin resistance syndrome: the controversy is dead, long live the controversy! Diabetologia 37: $956-958$ 
6. Reaven GM, Laws A (1994) Insulin resistance, compensatory hyperinsulinaemia, and coronary heart disease. Diabetologia 37: 948-952

7. Reaven GM (1995) Pathophysiology of insulin resistance in human disease. Physiol Rev 75: 473-486

8. Mahley RW, Rall SC (1995) Type III hyperlipoproteinemia (dysbetalipoproteinemia): the role of apolipoprotein $\mathrm{E}$ in normal and abnormal lipoprotein metabolism. In: Scriver CR, Beaudet AL, Sly WS, Valle D (eds) The metabolic and molecular bases of inherited disease, 7th edn. McGraw-Hill, Inc, New York, pp 1953-1980

9. Krauss RM, Levy RI, Frederickson DS (1974) Selective measurement of two lipase activities in postheparin plasma from normal subjects and patients with hyperlipoproteinemia. J Clin Invest 54: 1107-1124

10. Van Heek M, Zilversmit DB (1990) Postprandial lipemia and lipoprotein lipase in the rabbit are modified by olive and coconut oil. Arteriosclerosis 10: 421-429

11. Belfrage P, Vaughan M (1969) Simple liquid-liquid partition system for isolation of labeled oleic acid from mixtures with glyceride. J Lipid Res 10: 341-344

12. Gundersen HJG, Bendtsen TF, Korbo L et al. (1988) Some new, simple and efficient stereological methods and their use in pathological research and diagnosis. APMIS 96: 379-394

13. Jaroß W, Honigmann G, Kunze D, Hildmann W, Trübsbach A (1984) Anleitungen für klinische laboratoriums-metoden. VEB Verlag Volk und Gesundheit, Berlin

14. Nielsen LB, Nordestgaard BG, Stender S, Kjeldsen K (1993) Aortic esterified cholesterol is not superior to total cholesterol as a measure of atherosclerosis severity in cholesterol-fed rabbits. Atherosclerosis 99: 133-136

15. Hansen BF, Mortensen A, Hansen BF, Ipsen P, Frandsen H, Nordestgaard BG (1994) Atherosclerosis in Watanabe heritable hyperlipidemic rabbits. Evaluation of macroscopic, microscopic and biochemical methods and comparison of atherosclerosis variables. APMIS 102: 177-190

16. Jacobsson LS, Persson K, Aberg G, Andersson RGG, Karlberg BE, Olsson AG (1994) Antiatherosclerotic effects of the angiotensin-converting enzyme inhibitors captopril and fosinopril in hypercholesterolemic minipigs. J Cardiovasc Pharmacol 24: 670-677

17. Norusis MJ and SPSS Inc. 6.0 (1993). SPSS for Windows. Base system's guide, release 6.0. SPSS Inc, Chicago, USA

18. Ryan BF, Joiner BL, Ryan TA Jr (1985) Minitab handbook, 2nd edn. Duxbury Press, Boston

19. Cohn JS, McNamara JR, Cohn SD, Ordovas JM, Schaefer EJ (1988) Postprandial plasma lipoprotein changes in human subjects of different ages. J Lipid Res 29: 469-479

20. Stout RW (1970) Development of vascular lesions in insulin-treated animals fed a normal diet. BMJ 3: 685-687

21. Falholt K, Alberti KGMM, Heding LG (1985) Aorta and muscle metabolism in pigs with peripheral hyperinsulinaemia. Diabetologia 28: 32-37

22. Falholt K, Cutfield R, Alejandro R, Heding L, Mintz D (1985) The effects of hyperinsulinemia on arterial wall and peripheral muscle metabolism in dogs. Metabolism 34: 1146-1149

23. Sato Y, Shiraishi S, Oshida Y, Ishiguro T, Sakamoto N (1989) Experimental atherosclerosis-like lesions induced by hyperinsulinism in Wistar rats. Diabetes 38: 91-96

24. Stary HC, Chandler AB, Glagov S et al. (1994) A definition of initial, fatty streak, and intermediate lesions of atherosclerosis. A report from the committee on vascular lesions of the council on arteriosclerosis, American Heart Association. Arterioscler Thromb 14: 840-856
25. Nordestgaard BG, Zilversmit DB (1988) Hyperglycemia in normotriglyceridemic, hypercholesterolemic insulin-treated diabetic rabbits does not accelerate atherogenesis. Atherosclerosis 72: 37-47

26. Genuth S (1996) Exogenous insulin administration and cardiovascular risk in non-insulin-dependent and insulin-dependent diabetes mellitus. Ann Intern Med 124: 104-109

27. The Diabetes Control and Complications Trial Research Group (1993) The effect of intensive treatment of diabetes on the development and progression of long-term complications in insulin-dependent diabetes mellitus. New Engl J Med 329: 977-986

28. Pyörälä K, Savolainen E, Kaukola S, Haapakoski J (1985) Plasma insulin as coronary heart disease risk factor: relationship to other risk factors and predictive value over 9.5 year follow-up of the Helsinki Policemen Study population. Acta Med Scand 701 [Suppl]:38-52

29. Eschwege E, Richard JL, Thibult N et al. (1985) Coronary heart disease mortality in relation with diabetes, blood glucose and plasma insulin levels. The Paris Prospective Study, ten years later. Horm Metab Res 15 [Suppl]:41-46

30. Welborn TA, Wearne K (1979) Coronary heart disease and cardiovascular mortality in Busselton with reference to glucose and insulin concentrations. Diabetes Care 2: 154-160

31. Zilversmit DB (1979) Atherogenesis: a postprandial phenomenon. Circulation 60: 473-485

32. Zilversmit DB (1995) Atherogenic nature of triglycerides, postprandial lipidemia, and triglyceride-rich remnant lipoproteins. Clin Chem 41: 153-158

33. Nordestgaard BG, Lewis B (1991) Intermediate density lipoprotein levels are strong predictors of the extent of aortic atherosclerosis in the St. Thomas's Hospital rabbit strain. Atherosclerosis 87: 39-46

34. Daley SJ, Herderick EE, Cornhill JF, Rogers KA (1994) Cholesterol-fed and casein-fed rabbit models of atherosclerosis. Part 1: Differing lesion area and volume despite equal plasma cholesterol levels. Arterioscler Thromb 14: 95-104

35. Tatami R, Mabuchi H, Ueda K et al. (1981) Intermediatedensity lipoprotein and cholesterol-rich very low density lipoprotein in angiographically determined coronary artery disease. Circulation 64: 1174-1184

36. Reardon MF, Nestel PJ, Craig IH, Harper RW (1985) Lipoprotein predictors of the severity of coronary artery disease in men and women. Circulation 71: 881-888

37. Steiner G, Schwartz L, Shumak S, Poapst M (1987) The association of increased levels of intermediate-density lipoproteins with smoking and with coronary artery disease. Circulation 75: 124-130

38. Krauss RM, Lindgren FT, Williams PT et al. (1987) Intermediate-density lipoproteins and progression of coronary artery disease in hypercholesterolemic men. Lancet II:6266

39. Phillips NR, Waters D, Havel RJ (1993) Plasma lipoproteins and progression of coronary artery disease evaluated by angiography and clinical events. Circulation 88: 27622770

40. Nestel PJ, Fidge NH, Tan MH (1982) Increased lipoprotein-remnant formation in chronic renal failure. New Engl J Med 307: 329-333

41. Kasama T, Yoshino G, Iwatani I et al. (1987) Increased cholesterol concentration in intermediate density lipoprotein fraction of normolipidemic non-insulin-dependent diabetics. Atherosclerosis 63: 263-266

42. Simons LA, Dwyer T, Simons J et al. (1987) Chylomicrons and chylomicron remnants in coronary artery disease: a case-control study. Atherosclerosis 65: 181-189 
43. Simpson HS, Williamson CM, Olivecrona T et al. (1990) Postprandial lipemia, fenofibrate and coronary artery disease. Atherosclerosis 85: 193-202

44. Groot PHE, van Stiphout WAHJ, Krauss XH et al. (1991) Postprandial lipoprotein metabolism in normolipidemic men with and without coronary artery disease. Arterioscler Thromb 11: 653-662

45. Ryu JE, Howard G, Craven TE, Bond MG, Hagaman AP, Crouse JR (1992) Postprandial triglyceridemia and carotid atherosclerosis in middle-aged subjects. Stroke 23: 823-828

46. Patsch JR, Miesenböck G, Hopferwieser Tet al. (1992) Relation of triglyceride metabolism and coronary artery disease. Studies in the postprandial state. Arterioscler Thromb 12: 1336-1345

47. Uiterwaal CSPM, Grobbee DE, Witteman JCM et al. (1994) Postprandial triglyceride response in young adult men and familial risk for coronary atherosclerosis. Ann Intern Med 121: 576-583

48. Karpe F, Steiner G, Uffelman K, Olivecrona T, Hamsten A (1994) Postprandial lipoproteins and progression of coronary atherosclerosis. Atherosclerosis 106: 83-97
49. Shaikh M, Wootton R, Nordestgaard BG et al. (1991) Quantitative studies of transfer in vivo of low density, Sf 12-60, and Sf 60-400 lipoproteins between plasma and arterial intima in humans. Arterioscler Thromb 11: 569-577

50. Nordestgaard BG, Wootton R, Lewis B (1995) Selective retention of VLDL, IDL, and LDL in the arterial intima of genetically hyperlipidemic rabbits in vivo. Molecular size as a determinant of fractional loss from the intima-inner media. Arterioscler Thromb Vasc Biol 15: 534-542

51. Rapp JH, Lespine A, Hamilton RL et al. (1994) Triglyceride-rich lipoproteins isolated by selected-affinity anti-apolipoprotein B immunosorption from human atherosclerotic plaque. Arterioscler Thromb 14: 1767-1774

52. Bradley WA, Gianturco SH (1994) Triglyceride-rich lipoproteins and atherosclerosis: pathophysiological considerations. J Intern Med 236 [Suppl]736: 33-39

53. Appleyard M, Hansen AT, Schnohr P, Jensen G, Nyboe J (1989) The Copenhagen City Heart Study, Østerbrounders $\varnothing g e l s e n$. A book of tables with data from the first examination (1976-78) and a five year follow-up (1981-83). Scand J Soc Med 170 [Suppl]41: 1-160 